\title{
PENGEMBANGAN PEDESTRIAN PATH KAWASAN STASIUN KERETA API - KOTA BARU MALANG DAN SEKITARNYA
}

\author{
A. Tutut Subadyo
}

\author{
Program Studi Arsitektur Universitas Merdeka Malang \\ tutut.subadyo@unmer.ac.id
}

\begin{abstract}
ABSTRAK
Kawasan Stasiun Kereta Api Kota Baru Malang (SKA-KBM) merupakan kawasan dengan volume pengguna dan aktivitas yang tinggi, namun fasilitas pedestriannya belum memadai. Kondisi tersebut berimplikasi pada kekurang nyamanan dan ketidak amanan pejalan kaki. Jalur pedestrian yang ada di kawasan tersebut pada titik-titik tertentu menyempit karena berbagi dengan fungsi lain seperti tempat parkir, pedagang kaki lima, terminal bayangan angkutan kota dan bis pariwisata, bahkan menjadi ruang tunggu stasiun. Ketidakteraturan yang ditimbulkan oleh pengguna jalur pedestrian menyebabkan nilai sejarah pada kawasan tersebut menurun. Oleh karena itu, langkah humanisasi melalui kajian pengembangan jalur pejalan kaki di kawasan ini sangat dibutuhkan. Penelitian ini bertujuan untuk mengembangkan jalur pejalan kaki pada kawasan SKA-KBM dan sekitarnya menjadi lebih fungsional, estetis, serta aman dan nyaman. Metode yang digunakan adalah deskriptif kualitatif, dimana hasilnya dijadikan acuan untuk mengembangkan jalur pedestrian berdasarkan konsep: ruang, tata hijau, sirkulasi, fasilitas dan kelengkapan jalan. Hasil yang diperoleh merupakan rencana pengembangan jalur pedestrian yang dilengkapi dengan fasilitas tempat duduk, halte, papan informasi, tempat parkir, dan stop area, serta fungsifungsi lain sesuai kebutuhan, yang menjadi pemberi identitas dan aksen kawasan. Pengembangan fasilitas pedestrian path didasarkan pada fungsi kenyamanan dan keamanan yang diwujudkan dengan memberikan kelengkapan informasi, pembentuk identitas, dan pelayanan yang dikembangkan berdasarkan tema-tema tertentu.
\end{abstract}

Kata kunci: kawasan, pedestrian, stasiun kota baru, malang.

\section{ABSTRACT}

Malang Kota Baru Train Station Area (MKB-TSA) is an area with a high volume of users and activities, but its pedestrian facilities are inadequate. These conditions have implications for the discomfort and insecurity of pedestrians. Pedestrian lanes in the area at certain points narrowed because of sharing with other functions such as parking lots, street vendors, shadow terminal of city transportation and tourism buses, and even become station waiting rooms. The irregularity caused by pedestrian path users causes the historical value in the area to decrease. Therefore, the humanization step through the study of the development of pedestrian paths in this region is needed. This study aims to develop pedestrian paths in the MKB-TSA and surrounding areas to be more functional, aesthetic, safe and comfortable. The method used is descriptive qualitative, where the results are used as a reference to develop pedestrian pathways based on the concepts: space, green layout, circulation, facilities and completeness of the road. The results obtained are plans to develop pedestrian pathways equipped with seating facilities, shelters, information boards, parking lots, and stop areas, as well as other functions as needed, which provide the identity and 
accent of the area. The development of pedestrian path facilities is based on the function of comfort and security which is realized by providing complete information, forming identity, and services that are developed based on certain themes.

Keywords: region, pedestrian, kota baru station, malang.

\section{PENDAHULUAN}

Stasiun Kereta Api Kota Baru Malang (SKA-KBM) merupakan stasiun ketiga di Kota Malang yang dibangun padan tahun 1876, melengkapi keberadaan stasiun Kota Lama dan stasiun Blimbing. Kawasan SKA-KBM merupakan satu rangkaian sekuensial ruang kota dengan Alun-alun Bunder (Jan Pieter Zoen Coen Plain) dan Idjen Boulevard. Pada tahun 1930 Thomas Karsten mengusulkan pemindahan orientasi arah hadap bangunan stasiun yang semula ke arah Timur (Jalan Panglima Sudirman) dipindah menghadap ke Barat dengan alasan orang yang datang melalui SKA-KBM langsung bisa melihat panorama "de liggende vrow - Gunung Kawn" yang sangat eksotik. Untuk memberikan kesan monumental dibangun jalan dengan taman di tengahnya (Jalan Kertanegara) menuju Alun-alun Bunder dan dilengkapi Taman Ronnggowarsito (sebagai taman kota terluas di Kota Malang). Stasiun ini merupakan satu-satunya stasiun kereta api di Indonesia yang didesain dengan terowongan penghubung antara peron 2 ke peron 3 karena pertimbangan militer untuk melindungi serangan udara pada waktu Perang Dunia ke II.

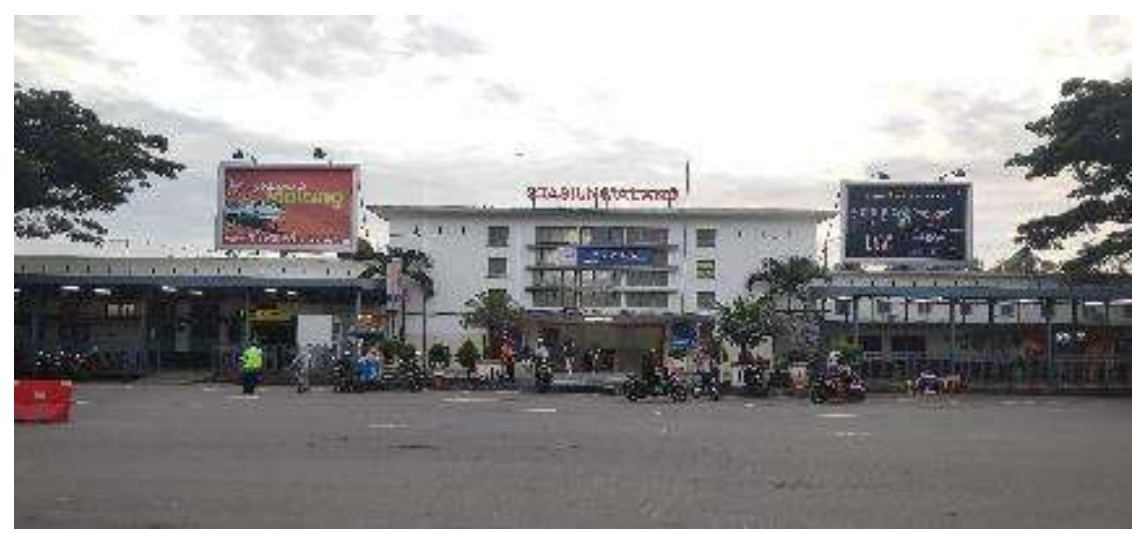

Gambar 1. Stasiun Kereta Api Kota Baru Malang dengan arsitektur kolonial yang bernilai sejarah

SKA-KBM yang berlokasi di Jl. Trunojoyo dengan tapak seluas 4,4 Hektar, memiliki pelayanan kereta api untuk perjalanan: Malang - Surabaya, Malang - Banyuwangi, Malang - Bandung, Malang - Yogyakarta, Malang - Surabaya - Semarang - Cirebon - Jakarta, dan Malang - Blitar - Tulung Agung - Kediri - Nganjuk - Madiun - Solo - Yogyakarta - Purwokerto - Jakarta. Untuk menuju kawasan SKA-KBM akses utamanya melalui Jalan Trunojoyo dan Jalan Kertanegara. Intersection jalur kereta api dengan jalan raya di wilayah Kota Malang terdiri atas 4 perlintasan persimpangan yakni 
flyover Arjosari dan flyover Mergosono serta underpass Patimura dan viaduct Panglima Sudirman (Bug Gludug).

Kawasan tersebut tingkat penggunaan dan penggunanya sangat tinggi. Penumpang harian pada awal tahun 2019 mencapai sekitar 15.000 hingga 30.000 orang penumpang per hari (KAI Stasiun Malang, 2018). Kondisi tersebut mempengaruhi kepadatan pengunaan fasilitas pedestrian path, yang kelancaran dan kenyamanan pejalan kaki nya sering terganggu dan kualitas lingkungannya mengalami penurunan. Karakteristik pedestrian path dapat diumpamakan sebagai aliran air, dimana pergerakannya akan mencari hambatan yang terkecil. Jalur yang diambil adalah jalur terpendek dari satu titik ke titik lainnya, sehingga sirkulasinya memotong rintangan di depannya (Subadyo, 2007). Ada dua aspek penting dalam sirkulasi pedestrian path yaitu aspek fingsional dan estetik, dimana keduanya harus diintergrasikan. Aspek fingsional berupa kenyamanan, keselamatan dan kepuasan sangat essensial dalam penataan sirkulasi pedestrian path. Sedangkan aspek estetikanya dapat diciptakan melalui penyusunan ruang dan pemandangan sepanjang tapak, sehingga tercipta peningkatan kualitas visualnya (Subadyo, 2008.a, 2008.b). Sekait dengan itu, menurut Nurisjah \& Pramukanto (1995), penggembangan pedestrian path menjadi suatu sistem yang nyaman menyenangkan dan aman dapat dilakukan dengan memanfaatkan topografi dan pemandangan sepanjang tapak. Bahkan pada beberapa tempat footways, dapat dijumpai aktivitas lain seperti berkumpul, ngobrol maupun bermain, merupakan hal utama dalam desain pedestrian path.

Menilik sejarah kawasan SKA-KBM dan melihat kondisinya saat ini telah terjadi degradasi nilai ruang sepanjang Jalan Trunojoyo (mulai dari perempatan jalan Patimura sampai pertigaan Jalan Panglima Sudirman/Bug Gludug) dan sisi timur Taman Ronggowarsito yang tersita untuk tempat parkir, tempat mangkal ojek online dan terminal bayangan angutan kota serta bis-bis pariwisata. Sejauh ini penataanya menelantarkan fungsi utamanya dan hanya bertumpu pada pertimbangan egoisme res economica semata. Ketidakteraturan pedestrian path menyebabkan nilai sejarah kawasan menurun. Bahkan eksitensi bangunan SKA-KBM tidak lagi dilihat nilai historis arsitekturnya, tetapi hanya dipandang sebagai bangunan transportasi biasa (Subadyo, 2008.b).

Oleh karena itu, langkah humanisasi melalui kajian pengembangan jalur pedestrian path di kawasan tersebut menjadi keniscayaan. Diperlukan studi pengembangan jalur pejalan kaki yang dapat memberikan kenyamanan dan keselamatan bagi pejalan kaki. Dengan kata lain penelitian ini bertujuan mengembangkan jalur pejalan kaki pada kawasan SKA-KBM dan sekitarnya sehingga diperoleh hasil yang fungsional dan estetis.

\section{METODE}

Lokasi penelitian kawasan SKA-KBM meliputi jalan Trunojoyo (mulai dari perempatan Jalan Patimura hingga pertigaan Jalan Gajah Mada dan jalan Panglima Sudirman - Bug Gludug), Jalan Kertanegara (mulai pertigaan Jalan Trunojoyo sampai ujung Barat Alun-alun Bunder), Jalan Ronggowarsito, dan Jalan Sriwijaya. Kawasan dibagi kedalam 5 segmen yaitu segmen A, B, C, D dan E. Pembagian kawasan dalam segmen didasarkan atas kesamaan kondisi pedestrian path. 


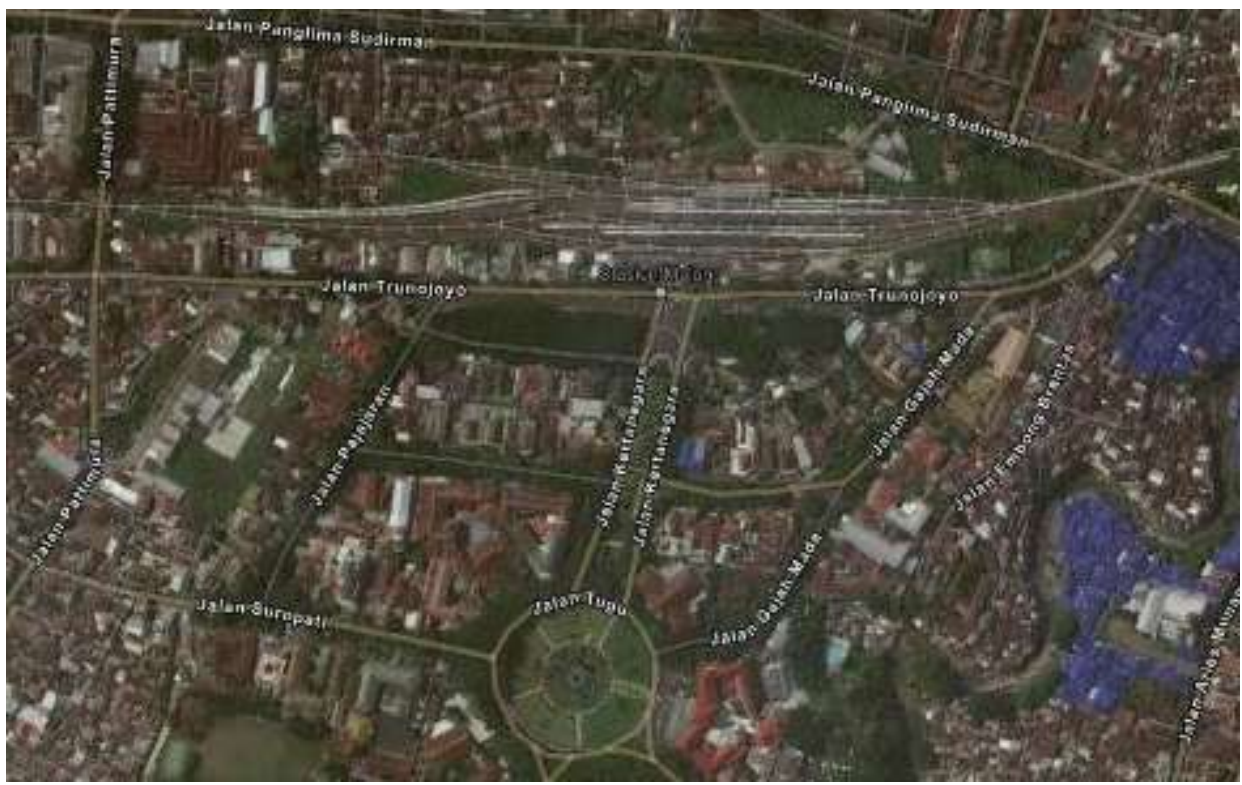

Gambar 2. Kawasan Stasiun Kereta Api Kota Baru Malang (SKA-KBM) dan sekitarnya

Tabel . 1. Pembagian Segmen pada Kawasan SKA-KBM

\begin{tabular}{|c|c|c|c|}
\hline No & Segmen & Lokasi & Keterangan \\
\hline 1. & $\mathrm{~A}$ & $\begin{array}{l}\text { Perempatan Jalan Patimura sampai simpang } \\
\text { tiga Jalan Pajajaran (Ruas Jalan Trunojoyo } \\
\text { sebelah Utara) }\end{array}$ & $\begin{array}{l}\text { Peruntukan lahan disisi kanan kiri jalan } \\
\text { campuran berupa perdagangan serta } \\
\text { pertokoan }\end{array}$ \\
\hline 2. & $B$ & $\begin{array}{l}\text { Simpang Tiga Jalan Pajajaran sampai } \\
\text { simpang tiga Jalan Kertanegara depan stasiun } \\
\text { SKA-KBM (Ruas tengah sisi Utara Jalan } \\
\text { Trunojoyo) dan Ruas Utara Jalan } \\
\text { Ronggowarsito }\end{array}$ & $\begin{array}{l}\text { Area dengan volume pengguna jalur } \\
\text { pejalan kaki yang cukup tinggi, peruntukan } \\
\text { perdagangan, pertokoan, dan } \\
\text { perkantoran. }\end{array}$ \\
\hline 3. & C & $\begin{array}{l}\text { Simpang tiga Jalan Kertanegara depan } \\
\text { stasiun SKA-KBM (Ruas tengah sisi Selatan } \\
\text { Jalan Trunojoyo) dan Ruas Selatan Jalan } \\
\text { Ronggowarsito }\end{array}$ & $\begin{array}{l}\text { Area dengan volume pengguna jalur } \\
\text { pejalan kaki yang cukup tinggi, dterdapat } \\
\text { pertokoan, perkantoran serta pusat kuliner, } \\
\text { dan Hotel Khasanah serta Pusat oleh-oleh, } \\
\text { dan Resto Ocean Garden. }\end{array}$ \\
\hline 4. & D & $\begin{array}{l}\text { Pertigaan depan Stasiun SKA-KBM } \\
\text { ujung Timur Alun-alun Bunder } \\
\text { Kertanegara) }\end{array}$ & $\begin{array}{l}\text { Sisis kanan dan kirinya merupakan area } \\
\text { campuran kuliner, perkantoran, sekolah, } \\
\text { DPRD Kota Malang }\end{array}$ \\
\hline 5. & $E$ & $\begin{array}{l}\text { Pertigaan Jalan Gajah Mada (Ruas Jalan } \\
\text { Trunojoyo sisi Selatan) sampai perempatan } \\
\text { Jalan Panglima Sudirman (Bug Gludug) }\end{array}$ & $\begin{array}{l}\text { Area perokoan, PKL, perdagangan, SPBU, } \\
\text { Viaduct }\end{array}$ \\
\hline
\end{tabular}

Sumber : Hasil Pengamatan Lapangan, 2019. 
Data primer diperoleh dari pengamatan visual, pencatatan dan dokumentasi kondisi, , aksesibilitas, visual tapak, persepsi dan keinginan pemakai jalan. Untuk mendapatkan pandangan pengguna didistribusikan kuesioner kepada 30 responden, yang ditentukan secara purporsive dan accidental sampling. Data sekunder diperoleh dari studi pustaka dan institusi terkait. Metode yang dipergunakan adalah metode deskriptif kualitatif. Hasil yang diperoleh dari analisis selanjutnya dijadikan acuan untuk pengembangan pedestrian path. Tahapan ini menghasilkan pengembangan berupa konsep ruang, tata hijau, konsep sirkulasi dan konsep fasilitas dan kelengkapan jalan.

\section{PEMBAHASAN}

Kawasan SKA-KBM merupakan salah satu area yang menjadi identitas Kota Malang. Selain terdapat stasiun kereta api, juga ada taman kota Ronggowarsito yang berperan menjadi pembentuk karakter lingkungan urban dengan tegakan pohon trembesi tua yang sudah ada sejak zaman kolonial. Tingginya jumlah pengguna jalan di lokasi ini mendorong masyarakat mengadakan kegiatan perekonomian, sehingga meningkatkan jumlah pengguna. Tercampurnya berbagai aktivitas juga memberikan dampak pada aliran sirkulasi pejalan kaki dan kendaraan bermotor serta sistem perparkirannya. Kendaraan diparkir disemua ruang dalam kawasan SKA-KBM sehingga membuat ruang pejalan kaki dari dan ke stasiun maupun pengunjung taman Ronggowarsito serta koridor Jalan Kertanegara menjadi semakin sempit. Hampir seluruh bahu jalan dipenuhi kendaraan yang parkir on street. Deskripsi koridor jalan dalam kawasan SKA-KBM dan sekitarnya adalah sebagai berikut.

Jalan Trunojoyo menjadi jalan utama pada kawasan SKA-KBM dengan panjang hampir satu kilometer, lebar jalur lalu lintas $8-10 \mathrm{~m}$, dan lebar trotoar 0,75-1,5 m. Jalan ini melebar pada pertigaan Jalan Pajajaran sampai pertigaan Jalan Gajah Mada. Jalan Ronggowarsito dan Jalan Sriwijaya memiliki lebar badan jalan $6 \mathrm{~m}$, lebar trotoar $0,85 \mathrm{~m}$ yang berbeda pada kiri dan kanan jalan. Sedangkan Jalan Kertanegara sebagai ruas pembentuk segmen D merupakan jalan bermedian di tengah yang berfungsi sebagai poros pembentuk ruang alun-alun bunder Tugu.

Tabel 2. Dimensi jalan Kawasan SKA-KBM

\begin{tabular}{cccccccl}
\hline No & Nama Jalan & \multicolumn{5}{c}{ Dimensi jalan (meter) } & Keterangan \\
\hline & & $\begin{array}{c}\text { Badan } \\
\text { Jalan }\end{array}$ & $\begin{array}{c}\text { Jalur } \\
\text { hijau tepi } \\
\text { jalan }\end{array}$ & Trotoar & $\begin{array}{c}\text { Saluran } \\
\text { drainase }\end{array}$ & $\begin{array}{c}\text { Median } \\
\text { jalan }\end{array}$ & \\
\hline 1 & Trunojoyo & 10 & $\begin{array}{c}0.75- \\
1.25\end{array}$ & $\begin{array}{c}1.4- \\
1.5\end{array}$ & $0.8-1.0$ & - & $\begin{array}{l}\text { Drainase tertutup, Jalur } \\
\text { hijau sisi Timur hanya } \\
\text { sebagian, tidak ada median } \\
\text { jalan }\end{array}$ \\
\hline 2 & Kertanegara & $2 \times 8$ & 1.25 & $1.5-$ & 1 & ada & $\begin{array}{l}\text { Kondisi trotoar baik, } \\
\text { boulevar median jalan } \\
\text { tertata dengan baik }\end{array}$ \\
\hline & Ronggowarsito & 6 & - & 1.5 & 0.8 & - & $\begin{array}{l}\text { Trotoar cukup memadai } \\
\text { kelengkapannya }\end{array}$ \\
\hline
\end{tabular}




\begin{tabular}{|c|c|c|c|c|c|}
\hline 4 & Sriwijaya & 6 & - & 0.75 & $\begin{array}{l}\text { Badan jalan dan Drainase } \\
\text { tertutup untuk lantai Sentra } \\
\text { Kuliner }\end{array}$ \\
\hline
\end{tabular}

Sumber : Hasil Pengamatan dan Pengukuran lapangan, 2019.

Hampir semua ruas jalan di kawasan SKA-KBM di lengkapi oleh fasilitas trotoar bagi pejalan kaki dengan lebar berkisar antara 0,5 m sampai dengan 2,0 $\mathrm{m}$ sesuai dengan lebar ruas jalannya.

Tabel 3. Dimensi Trotoar Pada Kawasan SKA-KBM

\begin{tabular}{|c|c|c|c|c|c|c|c|c|}
\hline \multirow{3}{*}{ No } & \multirow{3}{*}{ Nama Jalan } & \multicolumn{6}{|c|}{ Trotoar } & \multirow{3}{*}{ Ket } \\
\hline & & \multicolumn{3}{|c|}{ Kiri } & \multicolumn{3}{|c|}{ Kanan } & \\
\hline & & $\begin{array}{l}\text { Lebar } \\
\text { (m) }\end{array}$ & Jenis & Kondisi & $\begin{array}{l}\text { Lebar } \\
\text { (m) }\end{array}$ & Jenis & Kondisi & \\
\hline 1 & Trunojoyo & 1,5 & C & $R \& S$ & 1,5 & $C \& U$ & $R \& S$ & - \\
\hline 2 & Kertanegara & 1,5 & U & B & 1,5 & U & B & - \\
\hline 3 & Ronggowarsito & 1,5 & $U$ & $S$ & 1,5 & $U$ & $S$ & - \\
\hline 4 & Sriwijaya & 1,5 & C & S & 1,5 & U & $S$ & - \\
\hline
\end{tabular}

Sumber : Hasil Pengamatan dan Pengukuran lapangan, 2019

$$
\begin{array}{ll}
\text { Keterangan: } & \\
B=\text { Baik } & C=\text { paving } \\
S=\text { Sedang } & U=\text { ampyangan bermotif } \\
R=\text { Rusak } &
\end{array}
$$

Pada segmen A (perempatan Jalan Patimura - pertigaan Jalan Pajajaran) keberadaan kualitas trotoarnya belum memadai, baik lebar maupun konstruksi lantainya. Jalur pejalan kaki pada sisi Timur maupun sisi Barat tidak berfungsi, karena sepanjang penggal ruas Jalan Trunojoyo tersebut fungsinya berubah menjadi tempat parkir sepeda motor, mobil, penempatan barang-barang dagangan pemilik toko, pedagang kaki lima, dan fungsi-fungsi lain yang tidak bertautan dengan pergerakan para pejalan kaki.
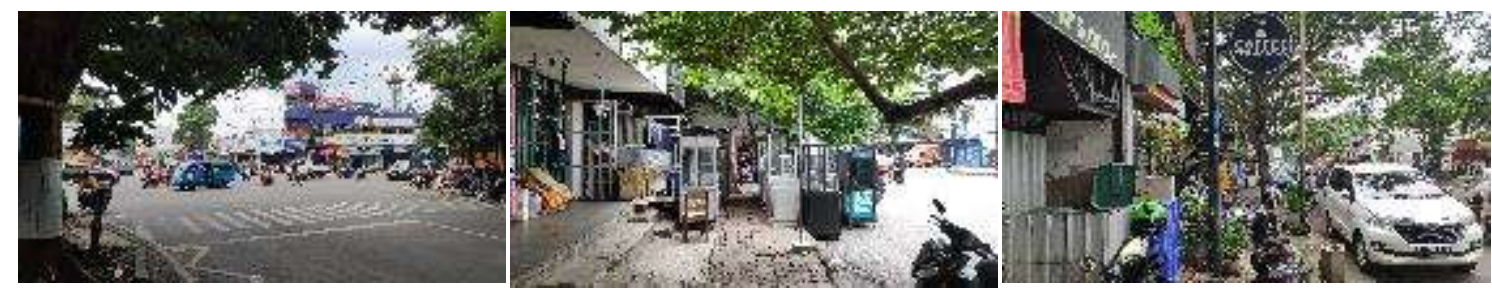

Gambar. 3. Ujung Segmen A Perempatan Jalan Patimura dengan Jalan Trunojoyo bagian

Utara kondisi trotoar banyak tidak berfungsi karena dipakai untuk memajang barang dagangan, tempat parkir sepeda motor dan PKL sehingga pejalan kaki harus berjalan di badan jalan. 
Terintervensinya ruang pedestrian path mengakibatkan pejalan kaki memilih untuk berjalan di badan jalan, sehingga membahayakan keselamatan dan keamanannya. Pohon tepian jalan pada segmen ini juga minim kalau ada juga masih muda, sehingga tidak ada ruang pernaungan dan perteduhan. Kelengkapan perabot jalan juga minim, kondisi visualnya banyak dipenuhi oleh polusi visual berupa papan reklame yang tidak beraturan dengan ukuran yang aneka ragam. Untuk itu perlu adanya penataan sistem perparkiran pada segmen A ini yang memberikan ruang khusus parkir yang dapat memberikan kenyamanan bagi pengunjung. Selain untuk mendukung aktivitas pengguna jalur pejalan kaki, diharapkan pengembangan pedestrian path di segmen A ini akan meningkatkan kualitas lingkungan sekitarnya.

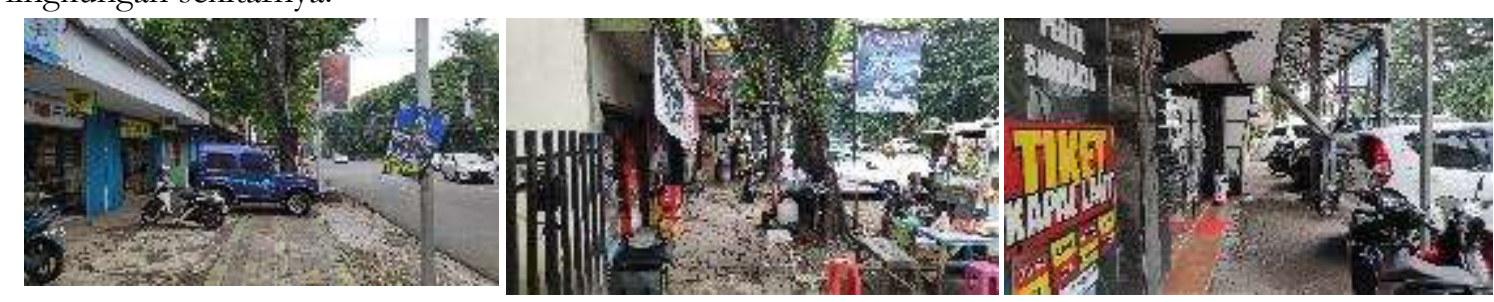

Gambar. 4. Keberadaan trotoar di Segmen A berubah fungsi menjadi tempat parkir sepeda motor dan mobil, bahkan badan jalannyapun ditempati untuk warung makan dan trotoar yang dikangkangi oleh tangga bangunan resto-cafe

Pada segmen B dan C kondisi ruangnya dapat disamakan, dimana pada sisi Timur Jalan Trunojoyo yang berhimpitan dengan bangunan sayap Stasiun sebelah kanan dan kirinya, hampir seluruh trotoarnya fungsinya tidak jelas. Hal ini terjadi karena seluruh bangunan sayap dari Stasiun disewakan oleh KAI untuk kegiatan perekonomian. Tidak adanya aturan yang jelas tentang kewenangan penggunaan bagunan sayap tersebut menjadi akar kesemrawutan fungsi yang mengakibatkan hilangnya fasilitas pedestrian path karena terintervensi oleh parkir kendaraan dan perluasan ruang berdagang penyewa kios pada bangunan sayap tersebut.
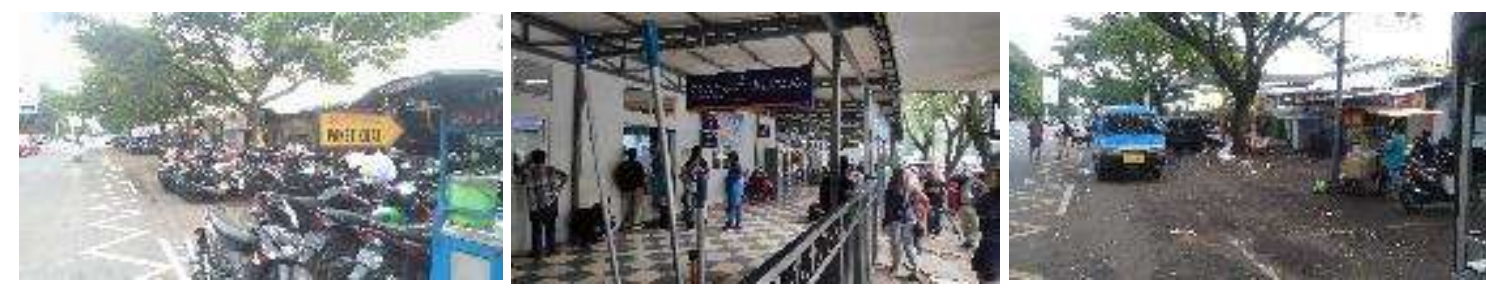

Gambar.5. Pada Segmen B dan C di sisi Timur Jalan Trunojoyo sepanjang tapak bangunan stasiun trotoarnya dberubah fungsi menjadi tempat parkir bahkan pada kiri kanan main entrance stasiun oleh KAI dibangun ruang tunggu calon penumpang.

Apalagi pihak KAI sendiri juga melakukan pengintervensian fasilitas pedestrian path disamping kanan kiri pintu masuk utama Stasiun dengan membuat bangunan permanen untuk ruang tunggu calon penumpang. Paripurnalah kemusnahan pedestrian path disepanjang penggal segmen ini, sehingga 
semua pejalan kaki hanya bisa berjalan kaki di badan jalan. Vegetasi pada sisi timur segmen B dan C yang ada hanyalah berupa tanaman hias (dalam pot), dan pohon trembesi yang masih muda. Pada sisi Barat dari segmen B dan C merupakan Taman Ronggowarsito yang keberadaan fasilitas pedestrian path nya memadai dan baik. Konstruksi lantai dan kelengkapan steet furniturenya relatif lengkap, bahkan site furniture yang ada di dalam tamannya sangat bervariasi, lengkap dan sangat baik. Untuk sisi ini fungsi trotoar relatif optimal. Keteduhan yang ada ternaungi pohon trembesi tua dalam taman sehingga tercipta suasana yang menyenangkan, dan menjadi tempat berkumpulnya orang. Dampak negatifnya kenyamanan pejalan kaki juga terganggu oleh berkerumunnya orang yang duduk-duduk bersantai di bawah patung Singa Edan. Ganggunan kenyamanan dan keamanan pejalan kaki pada segmen ini terjadi karena kehadiran terminal bayangan tempat mangkal angkutan kota dan bis-bis pariwisata serta main entrance Sentra Kuliner Sriwijaya.
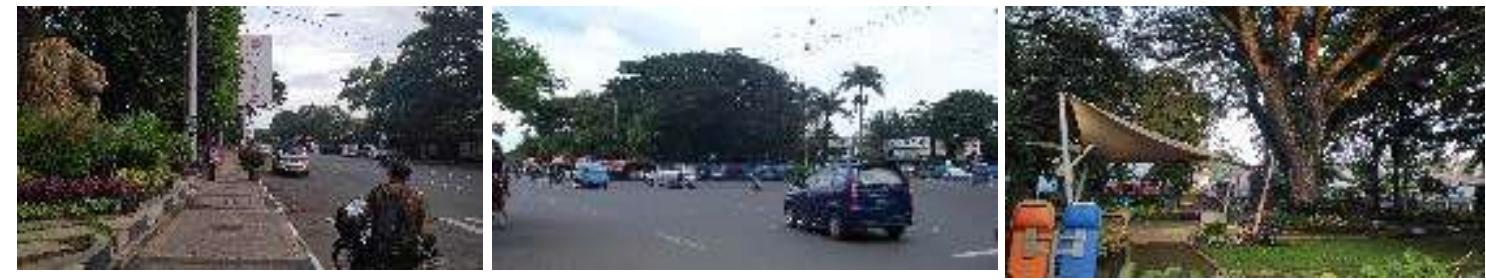

Gambar. 6. Trotoar di Segmen B dan C pada sisi Taman Ronggowarsito yang cukup bagus dengan pernaungan pohon-pohon besar seperti trembesi. Namun pada sisi ujung selatan pertigaan jalan terdapat penumpukan angkutan kota dan bis pariwisata yang menunggu penumpang dari stasiun, sehingga mengganggu kenyamanan dan keamanan pejalan kaki.

Keberadaan ruang parkir on street di sisi Timur taman Ronggowarsito sebelah Selatan menimbulkan kesemrawutan lalu lintas pada waktu kedatangan kereta api, dimana para sebagian besar penjemput parkirnya diseberang jalan tersebut. Trotoar yang berada disamping tempat parkir relatif sangat sempit tidak dapat untuk jalan bersisian dengan nyaman, sementara itu untuk pagar yang berada pada trotoar kawasan ini, yang sebenarnya dimaksudkan untuk melidungi pengguna jalur pejalan kaki, malah menjadi penghambat sehingga pejalan kaki memilih untuk berjalan pada badan jalan.
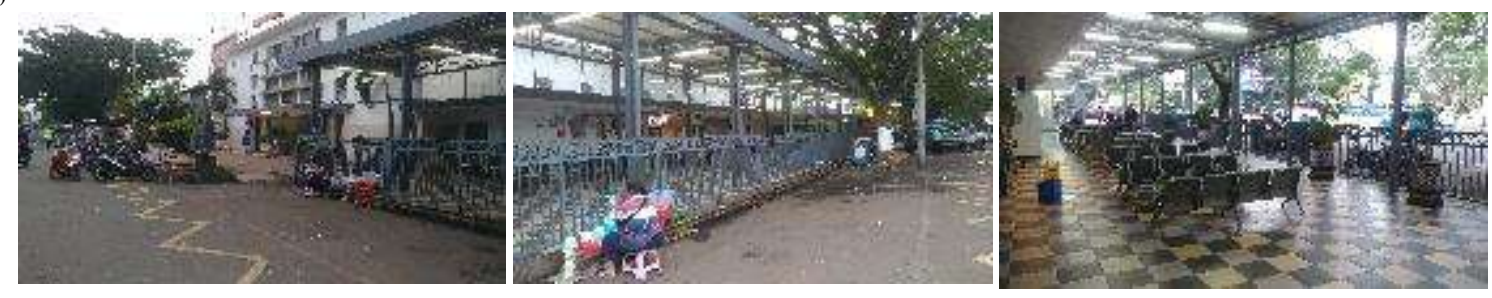

Gambar 7. Jalur pedestrian di depan bangunan Stasiun yang diintervensi menjadi ruang tunggu penumpang, menjadi contoh serius permasalahan hak pejalan kaki yang terampas di kawasan ini. 
Pada segmen B disisi Barat Jalan Ronggowarsito sebelah Utara terdapat beberapa pedagang kaki lima. Di bidang ruas koridor jalan ini juga terdapat kantor jasa, tempat bimbingan belajar BTC, Neutron, dan lain-lain juga menyebabkan sesaknya area ini. Masalah yang lain adalah kurang baiknya kondisi drainase pada area ini, sehingga sering terjadi genangan air jika hujan turun cukup deras. Sedangkan di sisi Barat segmen C yakni Jalan Sriwijaya berfungsi sebagai Sentra Kuliner sehingga fasilitas trotoar dan pedestrian path nya tidak berfungsi lagi.

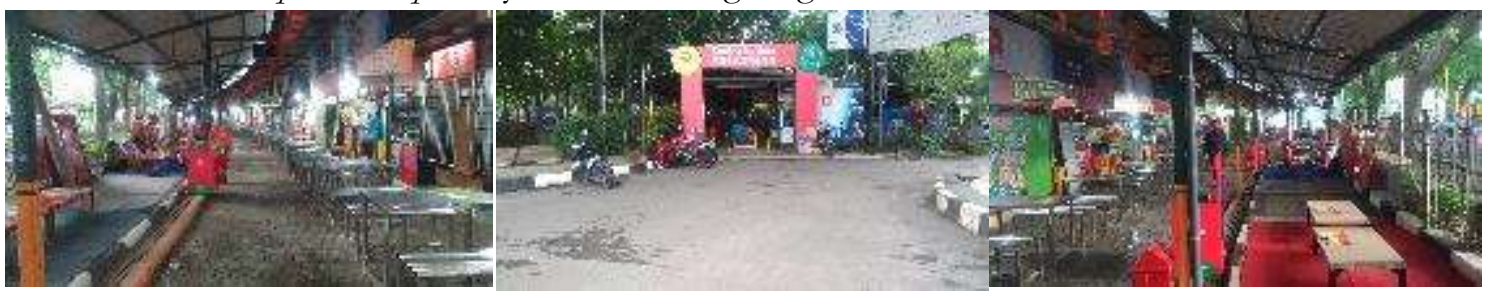

Gambar 8. Jalan Sriwijaya yang berubah fungsi menjadi Sentra Kuliner, menjadi permasalahan lain mengenai hilangnya hak para pejalan kaki di kawasan SKA-KBM.

Segmen D adalah ruas koridor Jalan Kertanegara (mulai dari ujung Timur Alun-alun Bunder hingga pertigaan Jalan Trunojoyo) kondisi jalur pejalan kakinya sangat baik. Vegetasi yang ditempatkan pada jalur hijau jalannya jug memberikan naungan pada pejalan kaki, drainase yang digunakan merupakan jenis drainase terbuka. Banyaknya aktivitas yang dilakukan menyebabkan sesaknya area oleh pengguna. Pengguna jalur pejalan kaki terdiri dari berbagai kelompok usia, mulai dari pelajar, pekerja dan lainnya. Jalur pejalan kaki digunakan oleh mereka untuk melintas dan menuju ke tempat lainnya.
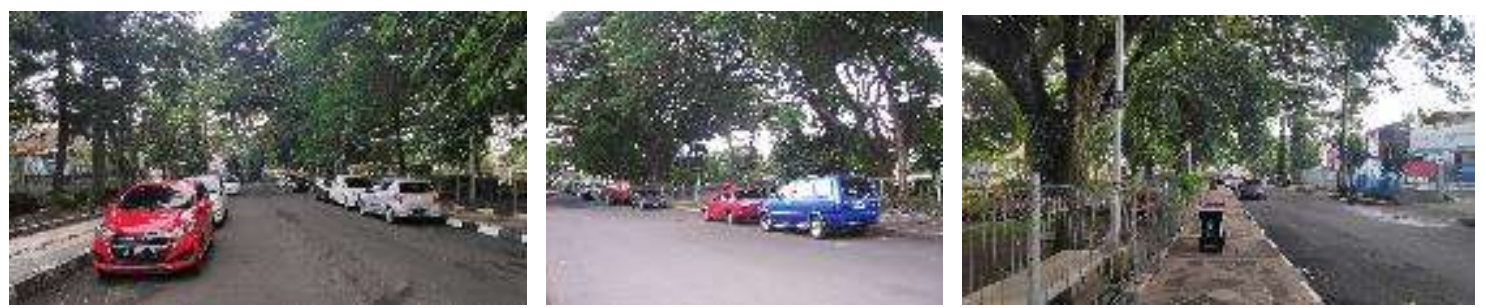

Gambar.9. Koridor Jalan Ronggowarsito sebagai pembatas Taman sebelah Barat dengan kualitas trotoarnya yang memadai juga sering ditempati oleh parkir kendaraan pengunjung tempat-tempat bimbingan belajar.

Hampir sebagian besar jalur pejalan kaki trotoarnya sering diintervensi aktivitas lain sehingga mereka menggunakan badan jalan untuk berjalan. Bahkan pada jam tertentu tepi jalan ini dipakai parkir bis sekolah Halokes yang jumlahnya $6-8$ bis. Dengan trotoar yang lebarnya hanya $1.25 \mathrm{~m}$ sedangkan jumlah pejalan kaki cukup tinggi, dan jalurnya pejalan kaki tertutup oleh fungsi lain, menjadikan badan jalan digunakan pejalan kaki untuk mempercepat pergerakan. 

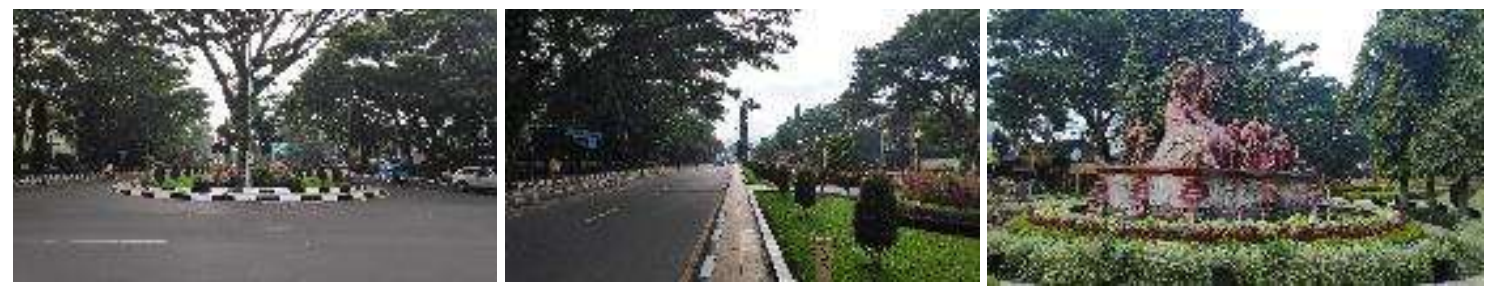

\section{Gambar. 10. Kelengkapan pedestrian path pada segmen D (Jalan Patimura Kertanegara) yang optimal fungsinya kecuali pada ujung pertemuannya dengan Jalan Trunojoyo di depan stasiun.}

Segmen E merupakan ruas koridor jalan Trunojoyo paling selatan yang dimulai dari pertigaan Jalan Sultan Agung sampai dengan perempatan Jalan Panglima Sudirman (Bug Gluduk). Keberadaan jalur pedestrian di segmen ini kondisi maupun kualitasnya kurang baik. Bahkan sebagian besar atau hampir seluruhnya menjadi ruang ekspansi dari pedagang helm dan barang-barang kelontong dan pada sisi sebelah selatannya dimanfaatkan sebagai SPBU dan PKL makanan dan minuman.

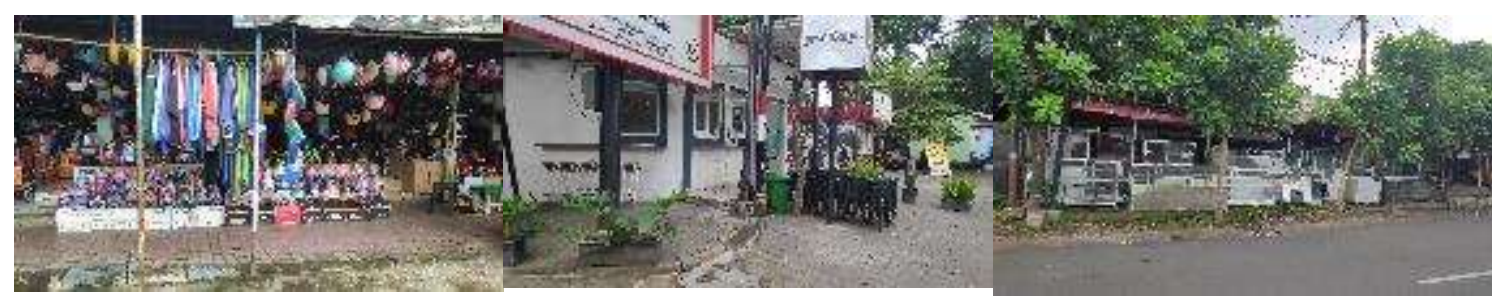

Gambar.11. Kondisi jalur pejalan kaki pada segmen E ini sebagian besar berubah fungsi untuk pedagang kelontong, makanan, minuman, dan menjadi sentra penjualan helm.

Tidak ada ruang bagi pejalan kaki di area ini.

Sebagian besar sisi jalan pada kawasan SKA-KBM telah ditanami dengan berbagai jenis tanaman, namun penataan kurang memperhatikan fungsi dan belum dapat mereduksi kebisingan dan polusi udara. Padahal hal tersebut sangat penting untuk menghindarkan pengguna dari bahaya cemaran udara yang ada. Untuk vegetasi pengarah dan peneduh yang ada perlu pemeliharaan yang optimal untuk mempertahankan kenyamanan. Pada beberapa bagian ruas jalan kecuali di segmen D, banyak ditemui aktivitas ekonomi berupa kios non permanen dan permanen dengan berbagai jenis barang yang dijual yang menempati trotoar. Hal ini menyebabkan jalan menjadi tidak teratur dan kumuh serta macet, sehingga perlu penataan ruang. Zebra cross hanya ada di bagian depan stasiun sehingga perlu adanya penambahan pada titik-titik tertentu sesuai dengan standar keamanan dan kenyamanan pejalan kaki.

Lebar trotoar pada kawasan SKA-KBM bervariasi antara 0,75-2,0 $\mathrm{m}$ juga dapat dikatakan kurang memadai. Hal ini terlihat dari banyak pejalan kaki yang menggunakan badan jalan. Selain itu, 
trotoar yang ada tidak mengakomodasi diffabel. Banyaknya angkutan kota yang berhenti menunggu atau sekedar menurunkan dan menaikkan penumpang di depan statiun diujung Selatan taman Ronggowarsito, perlu ditata agar tidak menimbulkan kemacetan atau kesemrawutan lalu lintas utamanya pada am-jam dimana kereta api datang maupun berangkat.

\section{Persepsi dan Preferensi Pengguna}

Dari hasil pendistribusian kuesioner diperoleh hasil, bahwa sebagian besar responden (59\%) menganggap pedestrian path pada kawasan SKA-KBM belum optimal. Pada Jalan Trunojoyo sebanyak $48 \%$ responden menyatakan kondisinya buruk dan cukup terik di siang dirasakan $52 \%$ karena minimnya pohon tepi jalan. Untuk keselamatan dan keamanan $64 \%$ dan $52 \%$ responden menganggap jalan ini terkategori berbahaya. Sebanyak 76\% menilai pemandangannya kurang menarik, dan $48 \%$ menilai jalan ini dianggap kotor.

Lebar pedestrian path di kawasan SKA-KBM ini dirasa sempit oleh $72 \%$ responden. Penataan lampu penerangan jalan ini menurut $48 \%$ responden belum tepat. Peletakan marka jalan dinilai sudah memadai oleh 44\% responden. Penempatan papan informasi dinilai belum tepat oleh 48\% responden. Keberadaan PKL pada kawasan dinilai sangat mengganggu oleh 48\% responden. Untuk kelengkapan fasilitas umum dan halte oleh $63 \%$ responden dinyatakan kurang memadai. Responden sebanyak $76 \%$ menginginkan pohon rindang (peneduh) untuk ditempatkan pada kawasan SKAKBM. Untuk jenis tanaman semak yang diinginkan beragam, namun $44 \%$ responden memilih semak yang dibentuk dan $32 \%$ responden menginginkan semak berbunga. Jenis ground cover berdauan indah diinginkan 54\% responden. Untuk penanaman, $67 \%$ responden memilih planter box sebagai media tanamnya. Bentuk penataan yang disukai oleh $68 \%$ responden adalah organik. Fungsi tanaman yang diinginkan paling banyak oleh responden adalah yang bisa mengurangi polusi dan menjadi identitas kawasan.

Dapat diinterpretasikan bahwa tanaman oleh pengguna dianggap penting keberadaannya. Tanaman pereduksi polutan adalah tanaman dengan daun bebulu kasar karena efektif untuk mengabsorsi polutan, debu serta jelaga (Subadyo, 2008 a). Dari uji sampel pada kawasan diperoleh tingkat kebisingan pada Taman Ronggowarsito mencapai 62,4-74,8dBA, dan di pertigaan Jalan Trunojoyo - Kertanegara mencapai 71,0-75,6 dBA. Pereduksian kebisingannya dapat dikontrol dengan tanaman berdasarkan intensitas, frekuensi dan sumber suara serta lokasi, tinggi, lebar dan kepadatan penanaman. Langgam dan gaya perabot jalan yang diinginkan bervariasi. Halte yang diinginkan oleh $92 \%$ responden beratap lengkap dengan tempat duduk. Motif permukaan lantai pedestrian path yang diminati oleh $87 \%$ responden adalah bercorak motif tertentu selaras dengan nilai kesejarahan kawasan. Sebanyak $74 \%$ responden menghendaki tempat parkir pada kawasan hanya pada tempat tertentu. Peletakan papan informasi dan tempat sampah yang diinginkan oleh $91 \%$ responden adalah tersebar dan teratur.

\section{PENGEMBANGAN PEDESTRIAN PATH}

Berdasarkan hasil analisis, maka pengembangan pedestrian path kawasan SKA-KBM direkomendasikan dengan mempertimbangkan fungsi-fungsi: (1) kenyamanan, (2) keamanan, (3) estetika, (4) identitas, (5) pelayanan, dan (6) penyangga. Fungsi-fungsi tersebut disesuaikan dengan 
kondisi lingkungan dan karakteristik kawasan SKA-KBM. Fungsi kenyamanan dan keamanan diterapkan diseluruh kawasan. Fungsi estetika diwujudkan pada bagian jalan dan jalur pedestrian path, yang dapat memberikan kesan menyenangkan bagi pengguna (utamanya pada segmen $\mathrm{B}, \mathrm{C}$, dan $\mathrm{D}$ ). Fungsi identitas diterapkan pada seluruh bagian jalan pada segmen B, C dan D, dengan desain yang harmonis dan menyatu tiap-tiap bagiannya, serta mengacu citra kawasan. Fungsi pelayanan diwujudkan pada daerah yang menunjang aktivitas utama pejalan kaki dan pengguna stasiun kereta api. Fungsi penyangga diwujudkan pada semua sisi jalan di kawasan SKA-KBM dan Taman Ronggowarsito serta boulevard Jalan Kertanegara.

Bertolak dari ungkapan di atas maka konsep pengembangan pedestrian path pada kawasan SKAKBM ditekankan pada aspek nyaman, aman, indah, berciri khas, dan identitas. Konsep terbagi atas : ruang, sirkulasi, seni tata hijau dan fasilitas. Aktivitas yang dikembangkan adalah : berjalan kaki (jumlah pejalan kaki, arah pergerakan, kualitas fisik jalur dan waktu serta lingkungan sekitar), pelayanan (menikmati bentang alam, duduk-duduk, beristirahat, menunggu kendaraan, naik dan turun kendaraan, berbelanja, makan minum, berdiskusi, berteduh), sosial (duduk-duduk, berbincang, beristirahat, interaksi antar pengguna), rekreasi pasif (menikmati pemandangan dari history area SKAKBM dan menikmati suasana era kolonial). Fokus ditekankan pada aspek sirkulasi yang memudahkan pengguna menuju dan meninggalkan kawasan, serta memberikan kenyamanan pengguna jasa kereta api. Penambahan fasilitas rekreasi diproyeksikan untuk menghidupkan dan memberikan nilai tambah kawasan yang menonjolkan nilai sejarah.

Olah Ruang. Penataan ruang pada kawasan SKA-KBM meliputi: (1) Ruang Sirkulasi bagi sirkulasi pejalan kaki dengan penambahan jalur pada beberapa titik dan pemanfaatan jalur pedestrian path pada jalan Kertanegara, Trunojoyo, Ronggowarsito, dan Sriwijaya sebagai upaya pengoptimalisasian main entrance ke stasiun; (2) Ruang pemisah jalur hijau sebagai pembatas sistem pedestrian path dengan sistem transportasi kendaraan, dan penambahan elemen softscape atau marka jalan. Ruang tersebut berada pada sisi kiri - kanan jalur pedestrian path jalan Trunojoyo dari pintu utama stasiun sampai perempatan Klojen - Jalan Patimura. Sementara itu pada jalan Ronggowarsito, ruang pemisahnya berupa planter box tanaman. ; (3) Ruang pelayanan berupa: (a) welcome space pembentuk citra dan kesan pertama pengunjung terhadap kawasan SKA-KBM. Ruang di persimpangan Jalan Trunojoyo dengan Jalan Kertanegara ini menjadi history area yang bersejarah dan berestetika tinggi, dan sebagai identitas kota. (b) Stop space dihadirkan ditepian Taman Ronggowarsito sisi Utara (sudut tempat patung Singa Edan) dan Selatan (tempat mangkal angkot dan bis pariwisata) untuk memenuhi kebutuhan rekreasi dengan melakukan aktivitas menunggu kendaraan, duduk-duduk, berbincang, dan beristirahat). (c) Comersial space untuk mengakomodasi aktivitas ekonomi yang berlangsung pada tapak bangunan stasiun, berkonsep semi outdoor dengan kios-kios serta jalur pejalan kaki yang nyaman. Aktivitas yang dihadirkan berupa cafe outdoor dengan life music dan aktivitas duduk-duduk menikmati pemandangan yang berada di sekitar tapak. Pada area ini juga ditambahkan pohon-pohon peneduh, lampu penerangan, dan peningkatan kualitas estetik berupa tanaman semak berbunga indah.

Sistem Sirkulasi. Konsep sirkulasi pada kawasan SKA-KBM merupakan jaringan sirkulasi yang memudahkan pejalan kaki untuk beraktivitas. Sirkulasi dibagi menjadi sirkulasi primer dan sekunder. 
Sirkulasi primer pada sistem pedestrian path (sisi kiri - kanan jalan Trunojoyo, Ronggowarsito, Sriwijaya, Kertanegara) ini mengakomodasi kebutuhan utama pejalan kaki (penyediaan ruang gerak untuk berjalan kaki dengan nyaman dan aman tanpa terputus oleh aktivitas). Sirkulasi sekunder (area perniagaan sepanjang Jalan Trunojoyo) yang terhubung dengan sirkulasi pejalan kaki dalam kawasan SKA-KBM sehingga pergerakannya menjadi tertib dan efisien.

Sistem pedestrian path pada kawasan SKA-KBM merupakan rangkaian jalur yang saling berhubungan secara kontinu sehingga memudahkan pejalan kaki dan memberikan rasa nyaman serta aman dalam berjalan kaki. Jalur pedestrian path eksisiting dipertahankan namun dilakukan perbaikan fisik seperti penggantian paving dan penambahan lampu penerangan. Sementara itu, penambahan jalur dilakukan di segmen B dan C untuk memenuhi kebutuhan jumlah pengguna jasa transportasi kereta api yang menuju dan meninggalkan statsiun.

Tabel 4. Lebar Jalur jalur Pedestrian Path Kawasan SKA-KBM

\begin{tabular}{lccc}
\hline \multicolumn{1}{c}{ Lokasi } & $\begin{array}{c}\text { Lebar awal } \\
\text { pedestrian path }\end{array}$ & $\begin{array}{c}\text { Lebar jalur } \\
\text { pengembangan } \\
\text { pedestrian path }\end{array}$ & Keterangan \\
\hline Jalan Trunojoyo & $0.8-1,5 \mathrm{~m}$ & $1.5-2.0 \mathrm{~m}$ & Lantai jalan bermotif \\
\hline Jalan Kertanegara & $1.5 \mathrm{~m}$ & $1.5-2.0 \mathrm{~m}$ & Lantai jalan bermotif \\
\hline Jalan Ronggowarsito & $1.0-1.5 \mathrm{~m}$ & $1.5-2.0 \mathrm{~m}$ & Lantai jalan bermotif \\
\hline Jalan Sriwijaya & $1.0 \mathrm{~m}$ & $1.5 \mathrm{~m}$ & Lantai jalan bermotif \\
\hline
\end{tabular}

Jalan Trunojoyo. Jalur pejalan kaki pada jalan ini dibagi menjadi tiga bagian yaitu bagian Utara, tengah (depan stasiun) dan bagian Selatan. Disisi Timur jalan ini, jalur pedestrian path berada di sisi bagian dalam sementara tanaman sebagai pemisah jalur pejalan kaki dan jalur kendaraan. Lebar minimal pedestrian path 0,75 - 1,5 m dengan perkerasan paving abu-abu tanpa motif. Bahan yang digunakan merupakan bahan yang dapat meresap air, memiliki variasi bentuk dan warna yang menarik serta tidak licin. Sedangkan pada sisi sebelah Barat terpenggal menjadi enam ruas yakni: simpang empat Jalan Patimura - ex Terminal Bis Patimura pertigaan Jalan Pajajaran - Simpangtiga Kertanegara Boulevard - pertigaan Jalan Sriwijaya pertigaan Jalan Gajah Mada - perempatan Bug Gludug. Keenam ruas tersebut memiliki jalur pedestrian path yang berbeda kualitas maupun kapasitasnya. Penataan dan pengembangan ada pada ruas Simpang Empat Jalan Patimura - ex Terminal Bis Patimura - pertigaan Jalan Pajajaran dan ruas pertigaan Jalan Gajah Mada - perempatan Bug Gludug. Jalur pedestrian bagian Utara diperbaiki kondisi fisiknya, serta penggunaan variasi warna yang menarik untuk menghilangkan kemonotonan. Penambahan elemen tanaman pengarah pada sisi Timur Jalan Trunojoyo untuk memberikan kenyamanan pengguna. Sementara itu pada bagian Selatan dari Jalan Trunojoyo ini diberi tanaman yang sama dengan jalur pedestrian path pada bagian Utara untuk menyatukan tema pada kawasan. Pemberian semak berdaun menarik juga digunakan untuk memperindah kawasan.

Jalan Kertanegara. Pada ruas jalan Kertanegara jalur pedestrian path nya didesain selebar $1.5-2.0 \mathrm{~m}$ untuk memberikan kenyamanan pada pejalan kaki. Penggunaan lantai jalan dengan disain yang menarik dipakai pada area ini untuk memberikan perasaan menyenangkan bagi para 
pejalan kaki. Selain itu pada Jalan Kertanegara juga dibuat jalur tambahan memotong boulevard di depan Bank Panin atau ujung Jalan Sultan Agung menuju ke sisi Utara (Resto Kertanegara dan SMA Negri 3). Sehingga dapat mendistribusikan pejalan kaki yang ingin menyeberangi boulevard Kertanegara. Penambahan jalur pedestrian path tersebut diperkaya estetikanya dengan memberikan ruang untuk penanaman pohon peneduh derta semak tanaman hias.

Jalan Ronggowarsito. Pada ruas jalan Taman Ronggowarsito ini, lebar jalur pedestrian path nya dibuat $1.5-2.0 \mathrm{~m}$ dengan penambahan elemen tanaman hias dan perabot jalan serta site furniture di dalam taman untuk menambah kesan dan nilai estetika kawasan. Pemberian saluran drainase tertutup pada ruas jalan ini untuk mengatasi masalah banjir yang sering terjadi pada kawasan ini. Masih adanya beberapa pedagang kaki lima pada jalur ini dipindahkan ke tempat lain atau disatukan di Sentra Kuliner Sriwijaya.

Jalan Sriwijaya. Pada ruas jalan Sriwijaya yang telah berubah fungsi menjadi Sentra Kuliner ini, perlu penataan kembali sehingga bisa juga berfungsi sebagai plaza wisata atau stop space bagi pengunjung kawasan SKA- KBM. Penambahan site furniture pada area ini menjadi kebutuhan untuk memperkaya peran dan fungsinya sebagai ruang rekreasi di kawasan tersebut.

Stop Space dan Commercial Space. Stop space dan commercial space merupakan area yang ditujukan bagi pengguna jalan khususnya pejalan kaki untuk beristirahat dan melakukan berbagai aktivitas seperti menunggu kendaraan, berbelanja, dan lain-lain. Stop space pada kawasan SKA-KBM ditempatkan pada sudut Taman Ronggowarsito sisi Utara (Patung Singo Edan) dan sudut sisi Selatan (tempat mangkal angkot - bis pariwisata dan halte Sentra Kuliner Sriwijaya) sebagai tempat menunggu para pengguna jasa kereta api yang menunggu jadwal keberangkatan kereta api ataupun sekedar duduk melepas lelah. Sedangkan commercial space tetap menempati sayap bangunan stasiun (sisi Timur Jalan Trunojoyo mulai dari depan pertigaan Jalan Pajajaran sampai dengan Bug Glugug). Letak Stop space dipilih tepat di depan muara mulut pintu utama stasiun, dengan fasilitas berupa sitting group dan halte untuk menunggu kendaraan bagi para pengguna jasa kereta api yang akan melanjutkan perjalanan. Bentuk stop space merupakan loop didesain menarik dengan peninggian lantai (anak tangga dibuat $15 \mathrm{~cm}$ ) dari badan jalan dan ramp dengan kemiringan $8 \%$ untuk diffabel. Tangga dilengkapi handrail untuk menjaga keselamatan pengguna. Planter box pada area ini untuk memberikan kesan yang lebih estetis, dan penerangan lampu pedestrian yang tersebar. Dilengkapi pula dengan shelter, papan informasi dan dilengkapi dengan tempat duduk didalamnya. Lantai stop space disusun dengan pola geometris dan warna yang menarik.

\section{Seni Tata Hijau dan Perabot Jalan}

Tata hijau kawasan SKA-KBM dikembangkan sesuai fungsinya sebagai komponen pedestrian path untuk memberikan kenyamanan dan pembatas fisik dan visual. Tata hijau ini dibagi ke dalam beberapa fungsi yaitu peneduh, pengarah, dan estetis. Tanaman yang dipilih adalah jenis peneduh dengan daya perangkap polutan yang baik serta memberikan naungan bagi pejalan kaki. Penyediaan perabot jalan dioptimalisaikan untuk mendukung aktivitas pengguna sehingga tercipta kesatuan rancangan sesuai dengan karakteristik kawasan stasiun kertea api untuk keseluruhan tema berdasarkan kebutuhan pengguna termasuk para difabel. 
Pengarah. Peletakan vegetasi pengarah dimaksudkan untuk mengarahkan kendaraan dan pejalan kaki. Penanamannya tidak menghalangi pandangan, dan dipilih pohon bertajuk tegak kolumnar di sepanjang sisi jalan yang ada di kawasan SKA-KBM (Trunojoyo, Ronggowarsito, Kertanegara, dan Sriwijaya). Pengkombinasian pohon dan semak dilakukan untuk menghilangkan kemonotan. Pohon yang digunakan berdiameter tajuk sempit $(\leq 5 \mathrm{~m})$, ditanam rapat dan pola penanamannya geometris.

Kenyamanan. Pohon Trembesi sebagai tanaman eksisting dipertahankan sebagai identitas. Jenis tanaman lain yang digunakan pada jalan Trunojoyo (perempatan Klojen hingga persimpangan jalan Panglima Sudirman -Bug Gludug) adalah tanaman Saputangan (Maniltoa grandiflora) atau Tanjung (Mimusops elengi), karena akarnya tidak merusak perkerasan. Sekaligus berfungsi sebagai pereduksi kebisingan dan pembentuk kesan dinamis dan luas sehingga mendukung aktivitas kawasan SKA-KBM. Pada area parkir di sebelah Barat stasiun, ditanam juga Trembesi (Samanea saman) dan Angsana (Pterocarpus indicus) yang dapat memberikan naungan.

Estetis. Tata hijau estetik ditempatkan pada jalur pejalan kaki dan area pada kawasan stasiun untuk menutup bad view.Tanaman Dadap Merah (Erythrina crista galli), diintervensikan untuk memberikan kesan tenang dan nyaman bagi pengguna jalan yang ingin beristirahat pada area ini. Pada area pedestrian plaza (di ujung pertemuan Jalan Kertanegara dan Jalan Trunojoyo - depan pintu masuk stasisiun) ditambahkan tanaman jakaranda (Jacaranda acutifolia) dalam planter box yang diberi pencahayaan uplighting untuk memberikan kesan menarik dan dinamis pada malam hari. Pada area parkir juga diletakkan planter bos berisi tanaman Taiwan Beauty (Cuphea.sp) dan Soka (Ixora sp) yang ditata secara berkelompok. Di sisi Timur jalan Trunojoyo sepanjang sayap bangunan stasiun dan Taman Ronggowarsito dan stop space diujung Jalan Kertanegara dan Jalan Sriwijaya, juga dihadirkan tata hijau estetis untuk menciptakan dramaturgi kawasan bersejarah tersebut.

Tempat Duduk. Jenis tempat duduk didesain berdasarkan kenyamanan dengan bentuk bervariasi mulai dari bahan hingga warna yang disesuaikan dengan tema disain ruang. Pada Taman Ronggowarsito dan Stop space yang menjadi history area, material yang digunakan adalah logam dengan disain kolonial dengan warna abu-abu kehitaman. Pada kawasan SKA-KBM, bangku-bangku ditempatkan dekat dengan pintu masuk stasiun dan dapat digunakan oleh pengguna untuk duduk dan menunggu. Bahan yang digunakan adalah logam dengan desain detailnya sederhana, dan warnanya disesuaikan dengan elemen lanskap lainnya. Penambahan fasilitas bengku dilakukan di semua area kawasan SKA-KBM, dengan tujuan memberikan ruang bagi masyarakat untuk berekreasi. Area aktivitas ekonomi - niaga dan rekreasi yang terletaksepanjang Jalan Trunojoyo pada sisi sebelah Timur juga dilengkapi dengan fasilitas bangku taman dan temapat duduk untuk mendukung aktivitas pengguna yang berada di dalamnya. Disain bangku dan tempat duduk dibuat berbeda sesuai dengan penempatannya pada masing-masing segmen.

Tempat Sampah. Untuk menjaga kebersihan kawasan SKA-KBM, tempat sampah diletakkan berdasarkan banyaknya aktivitas, dan dibagi atas 2 jenis yaitu sampah organik dan anorganik, serta dilengkapi dengan informasi jenis sampah sehingga pengguna mudah memahami secara tepat kemana harus memasukkan sampah ke dalamnya. Peletakannya didasarkan atas kemudahan jangkauan dan tempat yang tidak mengganggu pemandangan visual. Fasilitas tempat sampah diletakkan diseluruh bagian dari kawasan SKA-KBM. Khusus pada segmen B dan C (area perniagaan dan petokoan di 
sepanjang sisi bangunan sayap stasiun) keberadaan tempat sampah disesuaikan dengan banyaknya toko, kios, bedak dan lapak yang ada.

Lampu. Kurangnya penerangan di beberapa titik pada kawasan SKA-KBM pada malam hari membahayakan keselamatan para pejalan kaki. Keberadaan elemen lampu memberikan kesan menarik. Khusus pada stop space, dan plaza pedestrian di sudut Taman Ronggowarsito sisi Utara (Patung Singo Edan) dan sudut sisi Selatan (tempat mangkal angkot - bis pariwisata dan halte Sentra Kuliner Sriwijaya - Jalan Kertanegara) dan depan main entrance stasiun yang menjadi history area, lampu dekoratif didesain dengan style sesuai dengan tema kawasan. Lampu arahnya memancar ke atas (uplighting) menyinari bagian-bagian pohon dan memberikan kesan estetis dan menyatu dengan arsitektur bangunan stasiun.
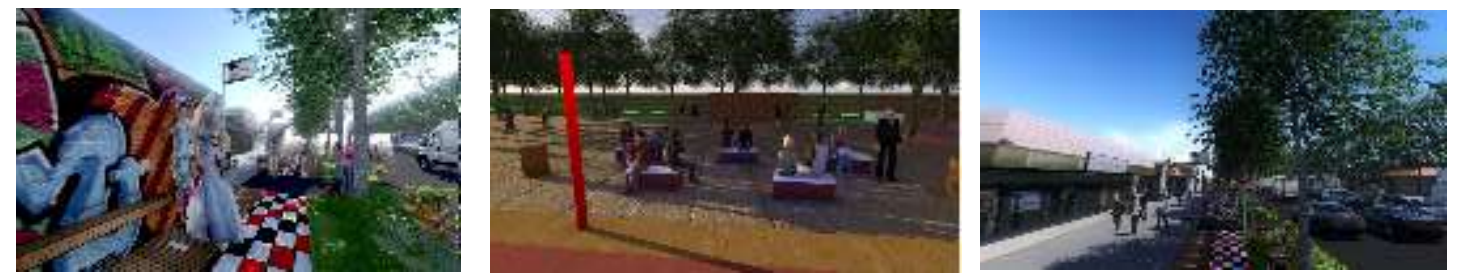

Gambar 12. Ilustrasi Pengembangan Pedestrian Path Kawasan SKA-KBM bertema Fashion Street

\section{KESIMPULAN}

Kawasan SKA-KBM memiliki volume pengguna dan aktivitas yang tinggi, dimana kondisi dan kualitas pedestrian path nya membutuhkan pembenahan. Kawasan dikembangkan sebagai taman pedestrian dengan penambahan soft material dan elemen keras di seluruh area agar dapat memberikan ciri, kenyamanan dan nilai estetik tertentu.

Konsep dasar pengembangannya bertujuan mewujudkan pedestrian path kawasan SKA-KBM yang nyaman, aman, indah dan memberi ciri serta identitas kota Malang dengan tema-tema disesuaikan dengan nilai kesejarahan dan nilai lainnya. Pengembangan fasilitas didasarkan pada fungsi kenyamanan, keamanan, informasi, identitas, dan pelayanan dengan tema modern klasik.

Konsep ruang dibagi atas ruang sirkulasi, ruang pelayanan, dan ruang identitas. Konsep tata hijau ditujukan untuk kenyamanan, pengarah dan estetika. Konsep sirkulasi dibagi atas sirkulasi primer (sirkulasi utama penghubung area-area pada kawasan SKA-KBM untuk ruang gerak perjalan kaki dengan nyaman dan aman) dan sirkulasi sekunder (sirkulasi alternatif bagi pejalan kaki dalam kawasan SKA-KBM agar tertib dan efisien).

\section{REFERENSI}

Direktorat Jenderal Bina Marga, Departemen Pekerjaan Umum., 1990. SK No. 011/T/BT/1995 tentang Tata Cara Perencanaan Fasilitas Pejalan kaki di Kawasan Perkotaan. Jakarta. 
Direktorat Jenderal Bina Marga, Departemen Pekerjaan Umum., 1999. SK No. 22/T/BM/1995 tentang Pedoman Teknik Persyaratan Aksesibilitas Pada Jalan Umum. Jakarta.

Nurisjah, Siti \& Q. Pramukanto. 1995. Perencanaan Lansekap. Departemen Arsitektur Lansekap. IPB Bogor.

Subadyo, A. Tutut., 2007. Pathway Corridor as a Place for Informal Settlements, paper presented at Meeting and Conference on Informal Settlements and Afordable Housing, 22 - 23 February 2007. Semarang (CIB - ITS Surabaya - Balitbang Pemda Tk I Jawa Tengah).

Subadyo, A. Tutut, 2008.a. Evaluasi Vegetasi pada Lansekap Koridor Jalan di Kota Malang. Makalah pada Seminar Nasional Pascasarjana VIII, ITS Surabaya , 13 Agustus, 2008.

Subadyo, A. Tutut., 2008.b. Pemanfaatan Lansekap Koridor Jalan Untuk Pengembangan Kota Ekologis. Makalah pada Seminar Nasional Eco Urban Design. Laboratorium Rancang Ruang Fisik Jurusan PWK Fakultas Teknik Universitas Diponegoro Semarang, 23 Oktober 2008. 